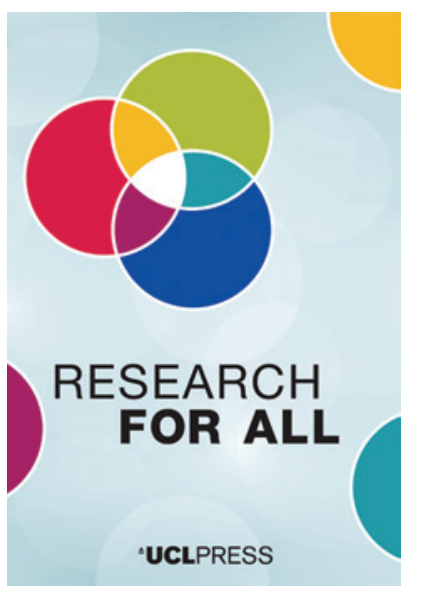

${ }^{ \pm}$UCLPRESS

RESEARCH FOR ALL

The open-access journal for public engagement with research

ISSN 2399-8121 (Online)

Journal homepage:

https://www.uclpress.co.uk/pages/research-for-all

\title{
From anonymous subject to engaged stakeholder: Enriching participant experience in autistic-language-use research
}

\section{Gemma Louise Williams iD}

\section{How to cite this article}

Williams, G.L. (2020) 'From anonymous subject to engaged stakeholder: Enriching participant experience in autistic-language-use research'. Research for All, 4 (2), 314-28. Online. https://doi.org/10.14324/RFA.04.2.13

Submission date: 27 August 2019

Acceptance date: 5 May 2020

Publication date: 22 September 2020

\section{Peer review}

This article has been peer-reviewed through the journal's standard double-blind peer review, where both the reviewers and authors are anonymized during review.

\section{Copyright}

(C) 2020 Williams. This is an open-access article distributed under the terms of the Creative Commons Attribution Licence (CC BY) 4.0 https://creativecommons.org/licenses/by/4.0/, which permits unrestricted use, distribution and reproduction in any medium, provided the original author and source are credited.

\section{Open access}

Research for All is a peer-reviewed open-access journal. 


\title{
From anonymous subject to engaged stakeholder: Enriching participant experience in autistic-language-use research
}

\author{
Gemma Louise Williams* - University of Brighton, UK
}

\begin{abstract}
The Talking Together community-engagement pilot project brought together pairs of autistic and non-autistic strangers to: (1) talk about their experiences of loneliness in their local city; and (2) think about potential, co-produced responses to the problem. The project had evolved as a secondary aim, from an initial need to acquire naturalistic conversation data for my linguistic $\mathrm{PhD}$ research investigating a theoretical reframing of autistic language use as 'different' rather than 'deficient'. The desire to make the data collection a meaningful experience for the participants in its own right was central to the research design, and so the Talking Together loneliness project was devised as a way to achieve this. However, it was not until the research was under way that the potential for valuable, immediate impact became apparent. This article reflects on the successes and challenges of the Talking Together pilot as a piece of autistic-led participatory research, and explores how the principles of engaged, participatory research can be applied so as to maximize impact, even where engagement may not be a primary aim. It also explores the 'participatory' nature of participatory research where the researcher belongs to the marginalized stakeholder group.
\end{abstract}

Keywords: loneliness, autism, conversations, participatory design, data collection

\section{Key messages}

- Engaged research can enrich linguistic data collection on multiple levels, not least in making the experience more meaningful for stakeholder research participants.

- Facilitating strangers to come together to talk about their experiences of loneliness can generate qualitative data on loneliness, while at the same time contributing to reducing the impact of loneliness, as an act of radical 'world building'.

- Supporting autistic people to access doctoral research opportunities is one way of broadening the body of participatory autism research.

\section{Introduction}

One of the most familiar characteristics of autism - even among those who know little about it - is a difficulty with social communication. In portrayals of autistically coded characters in film and media, it is something of a popular trope (for example, Raymond in Rain Man, Sheldon Cooper in The Big Bang Theory, Christopher in The Curious Incident of the Dog In the Night-Time). Within the sciences, since Kanner's (1943) early 
observations, there has been a long-held belief that the 'pragmatic' (that is, social/ contextually bound) communication of autistic people is impaired (for example, see Tager-Flusberg, 1999) - something that is usually attributed to a presumed theory-ofmind deficit (for example, see Baron-Cohen et al., 1985; Happé, 1993).

However, a growing body of empirical work investigating the 'double empathy problem' (Milton, 2012; Milton et al., 2018) is beginning to demonstrate that the difficulties in mutual understanding in fact run both ways between autistic and non-autistic people (for example, see Brewer et al., 2016; Heasman and Gillespie, 2018; Morrison et al., 2019; Sasson et al., 2017; Sheppard et al., 2016). The primary aim of my PhD research was to bring this difference-not-deficit perspective to an investigation of adult autistic language use, using cognitive linguistic theories to explore the breakdowns in understanding that occur at a pragmatic level between autistic and non-autistic people.

In order to do this, I first needed a body of naturalistic conversation data to analyse. Often, in autism research, conclusions are drawn from data derived from experimental settings. Corpora featuring naturalistic adult autistic conversation are not widely available, and where linguistic research has used naturalistic data as its source material (such as in Loukusa et al., 2007; Ochs and Solomon, 2010; Gainer Sirota, 2010; Sterponi and De Kirby, 2016; Sterponi and Fasulo, 2010), the conversations are usually between autistic children and their caregivers, captured by researchers as ordinary life goes by.

Deciding, then, to create my own data set from scratch, it felt important to ensure that the data-collecting activity was meaningful in its own right. In this way, the research project could become a mutually beneficial endeavour to both me as researcher and the autistic participants who were lending me their time. Co-production with autistic stakeholders, and autistic scholarship that brings autistic voices into the academy, are, rightly, increasingly being recognized as providing vital insights for autism research (Chown et al., 2017; Happé and Frith, 2020; Milton and Bracher, 2013; Pellicano, 2020). However, it remains the case that 'the vast majority of research in autism is still undertaken on autistic people, rather than with them, and is often not concerned with improving the day-to-day lives of people with autism' (Milton and Bracher, 2013: 2). With this in mind, I wanted to create a scenario where the conversations I was collecting for my primary linguistic analysis had an intrinsic value for the autistic people taking part in them.

Loneliness is something that I have been personally very familiar with for as long as I can remember (despite being blessed with a coterie of caring friends). This is not at all uncommon for autistic people, such as myself. A pervasive sense of not fitting in, divergent needs and ways of being in the world that are often misunderstood, and social isolation all contribute to autistic people in the UK being four times as likely to experience loneliness as the general population (National Autistic Society, 2018). Recent research findings, such as how non-autistic people tend to form instant, negative, thin-slice judgements about their autistic peers (Sasson et al., 2017), and how non-autistic perceptions and biases have a greater role in shaping interaction than actual autistic characteristics (Morrison et al., 2019), paint a bleak picture of the kind of additional commonplace, implicit social exclusion that autistic people can face daily.

Around the time that I was beginning to design the empirical part of my PhD research, BBC Radio 4 began broadcasting a series of programmes called The Anatomy of Loneliness, presenting the results of the BBC Loneliness Experiment. The experiment took the form of a large-scale survey, completed by 55,000 people over the age of 16, co-run by researchers from the University of Manchester, Brunel University London and the University of Exeter, and supported by the Wellcome Collection. The questionnaire asked people what they thought loneliness was, when they felt lonely and for how long. Surprisingly, the highest levels of loneliness were 
reported in younger respondents (16-24 age group), with 40 per cent feeling lonely, compared with only 27 per cent of older respondents who had completed the study (Hammond, 2020).

One further negative autism trope is that autistic people are unaffected by the human need for others - that we are quite happy alone in our own worlds. This, too, relates to a central explanatory theory of autism that gained traction for some time, postulating that the social difficulties observed in autistic people were born of a pathologically reduced motivation to engage in the social world (Chevallier et al., 2012). This idea no longer holds as much favour as it once did (Jaswal and Akhtar, 2019), particularly because it does not chime with the experiences of autistic self-advocates, who have more recently found a public voice and who often report a longing for social connection (see Causton-Theoharis et al., 2009).

Knowing that I would need non-autistic participants to take part in the necessary conversations, and that these participants would most likely be recruited from the available pool of University of Brighton humanities undergraduate students, loneliness suddenly seemed the most obvious focus for these exchanges. Here, two populations who are at increased risk of experiencing loneliness (young people, as identified by the BBC Loneliness Experiment, and autistic people) could meet and share their experiences and insights. Connections might be made between members of two social groups that may not ordinarily interact, broadening social horizons, and some valuable qualitative data addressing the lived experience of autistic loneliness might be created. It was out of this requirement for a data set of naturalistic conversational data, and the strong desire to make whatever conversations that might take place meaningful in their own right, that the Talking Together project was born.

\section{The Talking Together project}

The Talking Together community-engagement project was structured to bring together pairs of autistic and non-autistic strangers to: (1) talk about their experiences of loneliness in their local city; and (2) think about potential, co-produced responses to the problem. The original wish for the project was that if some clear aims for local actions on loneliness could be identified through these conversations, funding would be sought to develop a second stage, where the original participants and further stakeholders could be supported to trial a social enterprise project of their own design, tackling loneliness locally. This potential second stage was beyond the scope of my PhD, and securing financial support for an extension of the project proved impossible at the time, despite several attempts. However, I believe gains were made in addressing loneliness on a micro-scale, among the participants of Talking Together, and these are discussed later.

The project's participants fell into three groupings. Group A were the core set of eight autistic participants (originally ten, but two had to withdraw on the day due to ill health), recruited through local autism charity, Assert. Assert (www.assertbh.org.uk) is a member-led organization, founded in 2002, which supports autistic people traditionally identified as being 'high functioning', or having Asperger's syndrome, along with their family members, partners or carers. It offers a range of services, including a monthly social drop-in, casework, support in accessing government or local council benefits, educational and life-skills courses to empower autistic clients and autism awareness-raising training for local organizations. The second group of young people, Group B, were recruited through the University of Brighton School of Humanities mailing list. The third group, Group X, represented the friend or family 
member that each of the core autistic participants had nominated to come as their first conversation partner.

The core autistic participants (and their chosen, familiar conversation partners) were invited to take part in a piece of doctoral research investigating autistic communication, in the form of a community-engagement project about loneliness in the local area. The non-autistic participants (Group B) were invited, in the first instance, to take part in a piece of doctoral research investigating communication between pairs of strangers, in the form of a community-engagement project about loneliness. Following their conversations, this group were advised that a key aim of the study had been to investigate how different types of people establish and maintain common ground in conversations, and, as such, their conversation partner 'may' have been autistic. (I wanted to allow my autistic participants to disclose their own diagnoses on their own terms, should they wish to, and to leave some room for ambiguity.) It was explained that this information had previously been omitted in order to avoid any potential biases or modifications of their natural speech. Consent to use the conversations was reconfirmed in light of the new information.

Each core participant (from Group A) had three conversations of approximately ten minutes each, first with their chosen, familiar conversation partner (from Group X), second with an autistic stranger (another $A$ ) and finally with a non-autistic stranger (from Group B). For each conversation pairing, a different set of two prompt questions was provided in order to give the participants somewhere to begin, although it was explained that the questions were just there as a guide and that it was not necessary to answer them directly. Prompts were designed to elicit personal experiences of loneliness, and thoughts about loneliness in Brighton and Hove more specifically, and to invite ideas about how to address those problems within the city.

Increasingly, autistic individuals are receiving their diagnoses later in life, despite autism being present from (at least) birth. As such, it is widely understood that there exists 'a lost generation of people who were previously excluded from a diagnosis', often exacerbated by the misdiagnosis of (in particular) women (Lai and BaronCohen, 2015: 1013), whose masking behaviours (see Hull et al., 2017) - in addition to diagnostic biases - made them harder to detect. And yet, achieving a diagnosis of autism in adulthood is not easy. In one study, conducted by the Social Care Institute for Excellence $(n=59)$, only 19 per cent of participants diagnosed as autistic in adulthood found accessing an adult diagnosis 'easy', with 81 per cent describing it as ranging from 'quite difficult' to 'not possible' (Taylor and Marrable, 2011: 18).

In view of this, stipulating that core participants must have a formal autism diagnosis seemed unnecessarily limiting. However, in order to add the results of this study to the wider literature surrounding autism research in a meaningful way, participants would be required to have a formal diagnosis of autism. This was one of several points throughout the data collection design process where it felt like the world of research and the lived world of the researched community were slightly at odds. Eventually, it was decided that information pertaining to diagnostic status would be collected based on the self-report of having received a formal diagnosis. All respondents reported a diagnosis of either autism level 1, autism spectrum condition or Asperger's syndrome - the various terminology reflecting the differing times at which they received their diagnoses. Aside from this, I chose to not impose any further (demographic) stipulations, so as to allow for as much variability as possible within what would be a small case study. Finding a group of 'typical' autistic people is almost impossible, given the characteristic heterogeneity of autism (for example, see Beardon, 2017; FletcherWatson and Happé, 2019). In some ways, then, allowing a degree of chance to play out 
in terms of who the eventual participants were was part of the purposefulness of the sampling. The eventual eight core participants were three white males (two roughly in their 50s, of whom one had additional learning difficulties, and one in his 40s) and five white females (one in her 20s, three in their 30s and one roughly in her 50s). All were British except the female participant in her 50s, who was French.

\section{Loneliness, "ethical loneliness" and world building}

Loneliness is a 'universal affliction' (McGraw, 1995: 43) that almost all people will have experienced at some point in their lives. For many, it is a more serious, pervasive and distressing state. Often described as the 'discrepancy between one's desired and achieved levels of social relations' (Perlman and Peplau, 1981: 32), loneliness is a risk factor for various health problems and increased mortality rates (see Binnie, 2019; Jeste et al., 2020; Holt-Lunstad et al., 2010; Valtorta et al., 2016; Wong et al., 2017).

'Loneliness', however, can refer to a range of experiences. And, as Wong and colleagues (2017) rightly wonder, if we take as a given the oft-cited Perlman and Peplau (1981) definition of loneliness as the gap between the number and kind of social relations that one has, and that one wants, does it entail that 'loneliness [is] experienced only as a result of deficits in interpersonal relationships?' (Wong et al., 2017: 1). In a recent opinion piece in JAMA Psychiatry, Jeste et al. (2020: 1) describe loneliness as a 'hard to detect and lethal behavioural toxin' contributing to the creeping figures of growing suicide and opiate epidemics. Speculating on its cause, they suggest an 'underlying thread of social anomie and disconnection' (ibid.).

Wong and colleagues (2017), in their cross-sectional, qualitative study investigating elderly loneliness in Hong Kong, came to the conclusion that a significant factor influencing the extent to which the elderly felt lonely was a sense of increased alienation from society as a whole. As they had entered their twilight years, these elders had experienced nationally insufficient care for older people, a growing distance between themselves and the rest of society, and a disintegration of their identity within society (ibid.: 7). They felt that their voices were not heard, and that their lives were now insignificant. They were experiencing some degree of what might be called 'ethical loneliness'.

It is this breakdown of a connection with humanity - a connection that ordinarily is upheld by moral, 'ethical' principles - that causes the deepest wound of loneliness. To feel one's needs and human rights shrugged off by others erodes one's sense of selfhood and value in the world, and it is this that Stauffer (2015) has termed 'ethical loneliness'. According to Stauffer, ethical loneliness is 'a form of social abandonment that can be imposed only by multiple ethical lapses' (ibid.: 2), and it is experienced when:

... a violated person or [a] member of a persecuted group, has been abandoned by humanity, or by those who have power over one's life possibilities. It is a condition undergone by persons who have been unjustly treated and dehumanized by human beings and political structures ... compounded by the experience of not being heard. (ibid.: 1)

While Stauffer's treatise mainly deals with ethical loneliness in the context of political injustice and extreme human rights violations such as torture, this kind of 'ethical loneliness' seems particularly relevant when thinking about loneliness and autism. Autistic people are routinely 'othered' in macro- and micro-social ways, as was highlighted by the findings of Sasson and colleagues' (2017) study mentioned above, showing that non-autistic people tend to form unconsidered, negative opinions about 
autistic individuals within the first few seconds of meeting them. Moreover, as are all disabled people, they are statistically more likely than non-autistic people to suffer abuse of some form or another (see, for example, Haruvi-Lamdan et al., 2020; Stalker and McArthur, 2012; Sullivan and Knutson, 2000).

The purpose of this paper is to reflect on the value and challenges of meaningfully engaging autistic participants in the creation of a conversational data set, not to report on the qualitative loneliness findings that the data set generated. However, some of the participants' comments provide useful insight into their experiences of what could be described as ethical loneliness, and in the spirit of allowing marginalized voices to be heard, a few short extracts are reproduced here.

One bilingual autistic participant in her early 50s ('A3'), in lamenting her lack of meaningful connections, described her difficulty in making friends:

... sometimes I have trouble to, erm, to have a conversation or be understood because I don't, $\mathrm{mm}$, have the same thought process? Which makes it weird sometimes and people are wondering 'what are you saying?' or 'I can't understand, what do you mean?' or, you know, those kind of things, and you have to break it down for people.

It never lasts, or people - once you leave [a job] - they just forget you. Or they say, 'give me your phone number', and then they never call, so I got used to it and I deleted a lot of phone numbers on my phone. It's stupid to pretend you have friends when you haven't got them.

Another participant ('A1'), an autistic man with additional learning difficulties, also in his 50 s, shared his confusion and sadness about the lack of support available when he needed it:

... with me having, erm, having, erm, autism, and learning disabilities, I mean, I understand a bit more about it today than I did do, but when I wasn't getting the support, I felt very lonely. ... You know, cos, er, you know, you know I didn't have any connection. ... I was crying out for that support.

... and when you phone it [a helpline] no one ever answers. I mean, I think someone will answer it eventually, but from my experience, no one's ever answered it. I've never actually spoken to a person on the other end of the line on this, what-whatever number it was. ... You know, if people are crying out for help because of how they feel and there's no help, then of course they're going to feel lonely or, you know, get into a state...

It is exactly this kind abandonment by those in a position to help that causes 'a loneliness more profound than simple isolation' (Stauffer, 2015: 5). Not being able to make yourself understood, and not being able to connect in a satisfying way with fellow humans, can create a deep pain of isolation. Not having this pain acknowledged can be experienced as soul-crushingly dehumanizing.

For Stauffer, being 'heard', particularly when wrongs have occurred, is a crucial step towards reconciling the pains of ethical loneliness and re-establishing trust in other humans, or, as she calls it, 'world building':

A survivor will need broad social support that functions as a promise that, though she was once abandoned by humanity, that will not be allowed to happen again. That is an act of world building, which is a cooperative enterprise, not a solitary endeavour. (Stauffer, 2015: 7) 
It is the promise of engagement with others, and the promise that previously ignored voices will now be heard and, importantly, listened to, that is most important for rebuilding connection with a world where all people do matter. World building is a healing, restorative process, involving radical conceptual change about who matters, who is safe, and who belongs in the world following an instance or period of profound disconnection from it. World building cannot be done alone: there must be the hand of another reaching out towards ours. 'My sovereignty depends', summarizes Stauffer (ibid.: 19). We live under the illusion that we are independent entities, but the maintenance of our well-being and our very existence is dependent upon an interconnected web of human (and, arguably, ecological) relations. At the time of writing this article, during a national 'lockdown' in response to an international pandemic, never has this been more tangible.

\section{Taking a participatory approach}

Participatory research is a methodology of which a central principle is the disrupting of the 'traditional power imbalance between researcher and participant' (Fletcher-Watson et al., 2019: 2). Closely aligned with the adopted call to arms of the critical disability studies movement of 'nothing about us without us' (see Charlton, 1998; Milton and Bracher, 2013), its often emancipatory aims (Bertilsdotter Rosqvist et al., 2019) are to co-produce research that is mutually beneficial for both researcher and participants.

Involving stakeholder voices in the various stages of research design and implementation is important. The alternative - an exclusion of such voices - is 'both ethically and epistemologically problematic, and constitutes a significant barrier to impact' (Milton and Bracher, 2013: 61). An example shared by Nicolaidis et al. (2011), in their paper reporting on the establishment of their community-based participatory research partnership 'AASPIRE' (the Academic Autistic Spectrum Partnership in Research and Education), demonstrates this clearly:

For example, the group reviewed a paper about an [sic] functional magnetic resonance imaging study whose results were popularized as proving that autistics do not daydream. These reports angered many autistic self-advocates who knew that they daydreamed and felt the research questions were less pressing than other issues affecting their lives. They questioned the validity of the results, noting that the protocols did not take into account literal interpretation of language or challenges related to task switching. They also felt the deficit-based language in the research paper was stigmatizing and the conclusions reinforced dehumanizing stereotypes. (Nicolaidis et al., 2011: 143-4)

For a group of people who already experience a great deal of misconceptions, social exclusion, stigma and lack of understanding (Causton-Theoharis et al., 2009; Morrison et al., 2019; National Autistic Society, 2018; Sasson et al., 2017), it seems all the more pressing to ensure that autistic voices are included in the production of knowledge relating to their lived experience(s).

A number of simple but considered steps were taken throughout the designing of the Talking Together project, guided by Participatory Autism Research: A starter pack (Pellicano et al., 2017), to make the research as accessible as possible. Participants were recruited through Assert, a trusted gatekeeper, who also hosted the Talking Together conversations, meaning that the venue and route to get there were familiar. Materials (such as the information sheets and consent form) were designed so as to maximize 
white space; plain English was used along with illustrative images; and a photograph of me - the as yet unknown researcher - was also included to help shape expectations.

Drawing on autistic involvement in the design of results dissemination is an important, though often overlooked, feature of truly participatory research (see Nicolaidis et al., 2019; Pellicano et al., 2017). All too often, research that is pertinent to the lives and well-being of autistic people and their families is stashed behind a journal paywall, and even when it is published with open access, the dense academic terminology makes it inaccessible to non-experts. For this reason, a follow-up 'sensemaking' meeting with the original participants was scheduled for nine months after the data collection to provide an opportunity for participants to discuss their experiences of taking part, for me to share the initial findings, and for us to consider means of accessible dissemination of the findings for a wider autistic public.

\section{Participatory "enough"?}

A recent editorial (Pellicano et al., 2018: 1) in foremost interdisciplinary autism research journal, Autism, takes as its starting point a change in the focus of the recommendations of the Interagency Autism Coordinating Committee (IACC, an autism research advisory board to the US government) for research to include an emphasis on 'efforts to improve services across the lifespan' of autistic people. From here, they argue that in order to achieve this, the input of autistic stakeholders with lived experience 'in the here-andnow' is essential at all stages of the research, from 'being a research participant in the orthodox sense to being actively involved in the design, implementation, interpretation and dissemination of the research itself' (ibid.: 1, 2).

Yet for relatively small-scale doctoral research, is it realistic to expect (of oneself) such a level of engagement throughout, from multiple autistic voices? How 'participatory' does participatory research have to be to 'count'? This question was deftly explored by Southby (2017) when reflecting on her experience as a PhD candidate undertaking research into the experiences of football fans with learning difficulties. Like Southby, I was the sole creator of priority-setting for my research, and of devising the research questions, and there was no stakeholder steering committee reviewing my research design. What is different, perhaps, is that I belong to the stakeholder group in question: I'm both autistic and a researcher.

In reflecting on the benefit - or otherwise - of leading research as a member of the researched community, it has been difficult to fully separate out my own 'lived experience' from what I have learnt from my personal engagement with said 'community'. The shaping of my research goals has no doubt been influenced by what I have learnt through my membership of what might be termed a loose, online 'autistic community' (Bagatell, 2010). Across social media, autistic adults with varying abilities and perspectives from around the world connect via the \#ActuallyAutistic and \#AutisticsInAcademia hashtags, and here I have borne witness to many debates about issues that, while they may not immediately affect me, are deeply important to others. Likewise, I have been steeped in the literature of critical autism studies (see Woods et al., 2018) and events organized by the Participatory Autism Research Collective (PARC), an autistic-led organization initially based at London South Bank University, which has the purpose of bringing autistic people, scholars, activists and early career researchers together (https://participatoryautismresearch.wordpress.com).

In terms of existing in a dual role as both autist and researcher, overall, I would like to think that it added value to the Talking Together project. It is hard to quantify, but in Talking Together, there was a great sense of camaraderie and togetherness that I 
was able to be part of and help co-create. I was there listening among the participants, rather than listening to them. We shared in our mutual understanding. In ethnographic terms, this study had the opportunity for a deeply emic perspective (that is, making sense of the participants and their data from an 'insider' perspective), rather than an etic one (that is, drawing conclusions and making assumptions from an 'outsider' view). This insider perspective allowed me to take simple steps to make the research as accessible as possible, and to create an 'autistic-friendly' space where participants could feel both at ease and welcome.

As well as benefits, there were several challenges, although these came exclusively as difficulties engaging with the university culture rather than with the delivery of the Talking Together project itself. For example, as a researcher heavily influenced by critical autism studies and critical disability studies, I felt strongly that paying for participant-contributors' time and lived experience expertise of being autistic was an essential mark of respect. The INVOLVE policy of the National Institute for Health Research, which outlines the fair payment of fees and expenses for members of the public engaging in health research (INVOLVE, 2010), sets a national standard hourly and daily rate that has been taken up by British autism research charity Autistica. Further national policies regarding the involvement of service users or target populations in research generally recognize that, as well as meaningful participation, appropriate payment should also be encouraged (see Rickard and Purtell, 2011; and Nicolaidis et al., 2019 for autism-specific guidelines).

The university's ethical guidelines, however, stated that financial rewards or inducements must not be offered. The rationale behind this, I believe, is so as to avoid coercion, and as such reflects a valid concern when conducting research that involves the public (and, in particular, a potentially 'vulnerable' public). The issue was further complicated by the fact that this research involved participants of three different types: local autistic members of the general public; students at the university; and an unknown group of familiar conversation partners chosen by the core autistic participants. Would it be ethical, or even reasonable, to pay only some of the participants for their time, even if the remunerating of autistic participants was permitted?

The deliberation over payment was one of several areas that revealed a point of tension between standard, generalized university ethics procedures, and research involving so called 'vulnerable' autistic participants that perhaps requires a more nuanced, and participatory-informed, approach. The resulting compromise for this particular study was to offer all participants reasonable travel expenses to and from the venue where the conversations would take place, with simple refreshments provided. This fulfilled the requirements of the university ethics panel, but it left me feeling as if I had not stood up for the rights of my autistic participants. This conflict of interests echoes Southby's (2017: 128) reflection that 'participatory research may juxtapose the institutional mechanisms surrounding a research degree and provide practical barriers to research-degree students'. Bertilsdotter Rosqvist et al. (2019: 1), too, note that 'academic systems ... can be a barrier to the inclusion of autistic voices'.

It also mirrors another, more personal, tension in the process of achieving ethical approval. The year that I was submitting my application saw a new piece of university-wide software introduced as a replacement of the previous Microsoft Word form. I found the software incredibly challenging to access. In part, this was because of ambiguous phrasing of some of the questions, but mostly it was the visual format and layout of the interface (the colours, the endless spidery boxes leading to further, floating, spidery boxes) that I found inordinately taxing. In the end, I had to request a deadline extension and the help of an advocate in order to complete it. So, while 
the content of my application was justifying at length how I was making documents, information and physical spaces accessible to my autistic participants, this left me feeling that neither this software nor this application process were designed with autistic people in mind. Where that left me, as an autistic researcher trying to navigate the academy, I was not quite sure.

There are manifold barriers - societal, environmental, financial and structural that make progression into the academy challenging for autistic people. Those who overcome these challenges, for example, the viva voce (Chown et al., 2016), and who obtain doctoral degrees, still rarely go on to obtain lecturing or research contracts (Barnham and Martin, 2017; Martin, 2017). The institution of the academy is, by its nature, constructed around (cognitive) norms (Bertilsdotter Rosqvist et al., 2019) that represent everything that the autist stands outside of, having been defined in opposition to them. Indeed, my own PhD journey has been hampered by unpredictable accessibility issues and lack of institutional understanding about autistic needs, and ways of being and working. Paradoxically, it may be that more autistic students are needed to progress through to doctoral status before the academic environment can adapt itself to supporting autistic scholars.

Is it sufficient, then, to say that because I (a lone researcher) am a member of the marginalized group I am researching, there has been autistic involvement at every stage of my research (as advocated by Pellicano et al., 2018)? In their starter pack, Pellicano et al. (2017: 2) remind readers that researchers, autistic and non-autistic alike, 'need to listen in order to appreciate the diversity of what it is like to be autistic'. I fear that in making the claim that my research is participatory, I may myself be indulging in a little of the tokenism so rightly criticized by participatory research proponents (such as Fletcher-Watson et al., 2019; Pellicano et al., 2017): in this case, tokenistically using the term 'participatory research'. This project most lacked participatory input in its design and in the devising of the research aims. A more thorough participatory approach might have sought guidance from stakeholder Assert members on priorities for conversation topics, for example, or even on the primary aims of my PhD research. I could have built in an autistic steering committee to provide input on the details of the research design.

However, a doctoral research project is necessarily constrained by time, finances and fledgling ability. And, as Southby (2017: 130) concluded:

While attempts at participatory research may often fall short of their desired goals, being puritanical or dogmatic about what is and is not 'participatory research' only serves as a straightjacket for well-meaning researchers and research that may produce valuable results.

Perhaps for now, and at this stage, this project has been - borrowing from Winnicott (1971) - participatory 'enough'.

\section{Outcomes: Making a data set multiply valuable}

In choosing to meaningfully engage autistic people with the creation of the data set of naturalistic conversational data, the data set became multiply valuable, with numerous outcomes achieved. In total, the Talking Together project generated 245 minutes of recorded and transcribed naturalistic conversation data for the primary linguistic analysis. It also yielded rich, qualitative data relating to experiences of loneliness in Brighton and Hove, available for a secondary thematic analysis (currently in progress). Community engagement around an important issue was realized, and in so doing, 
meaningful interactions between strangers were facilitated, as evidenced by the extremely positive immediate feedback from participants. In addition, a new working relationship between the university and a community partner (Assert) was established, with scope for that to be developed.

Where loneliness represents 'an emotional hunger for intimacy [and] meaning' (McGraw, 1995: 44), meaningful connection with others is rich nourishment. In Binnie's (2019) Writing Back project, where she partnered members of the local elderly population with student pen pals as a means of collecting qualitative data about loneliness, she found that by engaging in the correspondence, both demographic groups experienced a positive influence on their mental health. The simple act of connecting with another human being, and feeling heard by another, can be a potent remedy. In Stauffer's (2015) terminology, this becomes an act of world building: an undoing of the pain of experiencing a disconnect with humanity.

This sentiment was reflected in the follow-up sense-making workshop that took place several months later. There were tears, and the general agreement that it had been 'a gift' to be able to share the burden of loneliness with another person. A participant described how a 'weight had been lifted off [her] shoulders' by being able to admit something of which she was usually ashamed (being lonely) to someone else, present and ready to listen. Many felt that talking to a stranger made the experience both easier and more profound.

Starting a conversation with anyone, taking time to think about why you are lonely and telling someone else that you feel lonely were three of the ten strategies identified in the BBC Loneliness Experiment to combat loneliness (Hammond, 2020). Talking Together created an opportunity for these three things - and many more - to occur, and in that sense it fulfilled its aim of tackling loneliness without needing to extend itself into a longer-term social enterprise response to local loneliness, as had been an original hope. The very act of 'talking together' functioned as a re-weaving of some of the rift between self and the human world, the perceived disconnection from which had created a sense of deep loneliness.

\section{Limitations}

One limitation of this pilot is the lack of objective quantification of impact. It was only once the first stage of the Talking Together project had begun that its potential significance as a piece of impactful engagement really became apparent. Participants were visibly moved by their experiences of taking part - there was raucous laughter, tears and plentiful hugs between people who, 15 minutes previously, were complete strangers - and many made a point of coming to tell me or my supervisor (who was also present) how much they had enjoyed Talking Together, and how useful an activity they thought it was.

Given that the primary aim of the project had been to collect naturalistic conversation data (albeit in a meaningful way), there was nothing built into the design to capture the immediate feedback of the participants in terms of engagement impact. In terms of public engagement activities, 'impact' is what occurs 'when public engagement gives rise to tangible benefits for people (such as enhanced well-being or educational attainment)', but these are 'typically difficult to evidence' (Reed et al., 2018: 146, discussing the 'Public Engagement Evaluation Toolkit' developed for Queen Mary University of London - www.qmul.ac.uk/publicengagement/goodpractice/evaluationtoolkit). Talking Together clearly had significant impact, and it is a regret that this rich and positive immediate feedback was not somehow recorded. 
After the first day of conversations, having witnessed the positive impact the project was having, I sought the approval of the university ethics committee to email out invitations to provide open-ended feedback (by return email), on the experience of participating, as a means of trying to capture this. As might be expected, the uptake of this was low. The enthusiasm of the moment is not something that can really be replicated, and why would participants feel the need to clunkily regurgitate the heartfelt comments that they had already shared with me in person? What I have learnt from this experience is that it would be wise for any participatory research to have built into the design a moment for some form of light-touch, in-the-moment feedback (of which there are many inspiring suggestions in the 'Public Engagement Evaluation Toolkit'; see Reed et al., 2018), regardless of whether or not 'engagement' is a primary aim.

\section{Conclusion}

In summary, the Talking Together project demonstrated that the application of engaged, participatory methodologies can enrich the data collection phase of a research project in ways that may not be immediately predictable. In making the conversation task meaningful in its own right, the data became multiply valuable: numerous additional outputs were generated, and the exercise became positively impactful for the stakeholder participants.

As to whether research is participatory 'enough' if the researcher belongs to the marginalized stakeholder group, it remains difficult to say. Being an engaged member of a researched community allows for intuitive understandings that non-members may have to work harder to achieve, and allows closer access to a range of perspectives from within that community. However, wherever possible, multiple perspectives should be sought throughout all stages of the research. Additionally, in terms of broadening the scope of participatory autism research, making universities and doctoral-level study more accessible to autistic researchers will help to bring more autistic voices into the academy, which will in turn help to shape research aims.

Recalling Stauffer's (2015) ethical loneliness, it is the promise of engagement with others, and the promise that previously ignored voices will now be heard, that is most important for rebuilding trust in a world where all people do matter. For a few days, Talking Together saw people - strangers - come together and share in their experiences of loneliness. People dared to speak, and dared to listen. In so doing, I believe, an act of world building took place.

\section{Acknowledgements}

With thanks to Assert Brighton and Hove for their gatekeeping role in the Talking Together project, and for the generous use of their premises. Special thanks to Dr Tim Wharton and Dr Caroline Jagoe for their input and guidance on the research design. Final thanks to the two anonymous reviewers, and the editor and associate editor of this journal, as well as to the UCL IOE Press Journal Reviews team for their helpful feedback and critique of the earlier draft.

\section{Notes on the contributor}

Gemma Louise Williams is a final-year University of Brighton doctoral studentship awardee. Her work investigates the breakdowns in mutual understanding between autistic and non-autistic people, using a synthesis of interdisciplinary tools and theories 
largely influenced by 'relevance theory'. A piece of Gemma's autoethnographic creative writing ('We're all strangers here') from her PhD thesis, documenting her experience of the Talking Together project, was awarded Honorable Mention in the Society for Humanistic Anthropology 2019 Ethnographic Fiction and Creative Nonfiction Prize.

\section{References}

Bagatell, N. (2010) 'From cure to community: Transforming notions of autism'. Ethos, 38 (1), 33-55. Online. https://doi.org/10.1111/j.1548-1352.2009.01080.x

Barnham, C. and Martin, N. (2017) 'Considering employment of young people with intellectual impairment and autism leaving school and college'. Autism and Intellectual Disability in Adults, 2 (1), 53-9

Baron-Cohen, S., Leslie, A.M. and Frith, U. (1985) 'Does the autistic child have a "theory of mind"?'. Cognition, 21 (1), 37-46. Online. https://doi.org/10.1016/0010-0277(85)90022-8

Beardon, L. (2017) Autism and Asperger Syndrome in Adults. London: Sheldon Press.

Bertilsdotter Rosqvist, H., Kourti, M., Jackson-Perry, D., Brownlow, C., Fletcher, K., Bendelman, D. and O'Dell, L. (2019) 'Doing it differently: Emancipatory autism studies within a neurodiverse academic space'. Disability and Society, 34 (7-8), 1082-101. Online. https://doi.org/10.1080/0968 7599.2019.1603102

Binnie, G. (2019) 'Loneliness and the letter: Co-developing cross-generational letter writing with higher education students and older people'. Research for All, 3 (1), 59-73. Online. https://doi.org/10.18546/rfa.03.1.06

Brewer, R., Biotti, F., Catmur, C., Press, C., Happé, F., Cook, R. and Bird, G. (2016) 'Can neurotypical individuals read autistic facial expressions? Atypical production of emotional facial expressions in autism spectrum disorders'. Autism Research, 9 (2), 262-71. Online. https://doi.org/10.1002/ aur.1508

Causton-Theoharis, J., Ashby, C. and Cosier, M. (2009) 'Islands of loneliness: Exploring social interaction through the autobiographies of individuals with autism'. Intellectual and Developmental Disabilities, 47 (2), 84-96. Online. https://doi.org/10.1352/1934-9556-47.2.84

Charlton, J.I. (1998) Nothing about Us without Us: Disability oppression and empowerment. Berkeley: University of California Press.

Chevallier, C., Kohls, G., Troiani, V., Brodkin, E.S. and Schultz, R.T. (2012) 'The social motivation theory of autism'. Trends in Cognitive Sciences, 16 (4), 231-9. Online. https://doi.org/10.1016/j. tics.2012.02.007

Chown, N., Beardon, L., Martin, N. and Ellis, S. (2016) 'Examining intellectual prowess, not social difference: Removing barriers from the doctoral viva for autistic candidates'. Journal of Inclusive Practice in Further and Higher Education, 6 (1), 22-38. Online. https://openresearch.Isbu.ac.uk/ item/87495 (accessed 22 June 2020).

Chown, N., Robinson, J., Beardon, L., Downing, J., Hughes, L., Leatherland, J., Fox, K., Hickman, L. and MacGregor, D. (2017) 'Improving research about us, with us: A draft framework for inclusive autism research'. Disability and Society, 32 (5), 720-34. Online. https://doi.org/10.1080/09687599 .2017.1320273

Fletcher-Watson, S., Adams, J., Brook, K., Charman, T., Crane, L., Cusack, J., Leekam, S., Milton, D., Parr, J.R. and Pellicano, E. (2019) 'Making the future together: Shaping autism research through meaningful participation'. Autism, 23 (4), 943-53. Online. https://doi. org/10.1177/1362361318786721

Fletcher-Watson, S. and Happé, F. (2019) Autism: A new introduction to psychological theory and current debate. London: Routledge.

Gainer Sirota, K. (2010) 'Narratives of distinction: Personal life narrative as a technology of the self in the everyday lives and relational worlds of children with autism'. Ethos, 38 (1), 93-115. Online. https://doi.org/10.1111/j.1548-1352.2009.01083.x

Hammond, C. (2020) 'Who feels lonely? The results of the world's largest loneliness study'. Online. www.bbc.co.uk/programmes/articles/2yzhfv4DvqVp5nZyxBD8G23/who-feels-lonely-the-resultsof-the-world-s-largest-loneliness-study (accessed 24 June 2020).

Happé, F.G.E. (1993) 'Communicative competence and theory of mind in autism: A test of relevance theory'. Cognition, 48 (2), 101-19. Online. https://doi.org/10.1016/00100277(93)90026-r

Happé, F. and Frith, U. (2020) 'Annual research review: Looking back to look forward - changes in the concept of autism and implications for future research'. Journal of Child Psychology and Psychiatry, 61 (3), 218-32. Online. https://doi.org/10.1111/jcpp.13176 
Haruvi-Lamdan, N., Horesh, D., Zohar, S., Kraus, M. and Golan, O. (2020) 'Autism spectrum disorder and post-traumatic stress disorder: An unexplored co-occurrence of conditions'. Autism, 24 (2), 884-98. Online. https://doi.org/10.1177/1362361320912143

Heasman, B. and Gillespie, A. (2018) 'Perspective-taking is two-sided: Misunderstandings between people with Asperger's syndrome and their family members'. Autism, 22 (6), 740-50. Online. https://doi.org/10.1177/1362361317708287

Holt-Lunstad, J., Smith, T.B. and Layton, J.B. (2010) 'Social relationships and mortality risk: A metaanalytic review'. PLoS Medicine, 7 (7), Article e1000316, 1-20. Online. https://doi.org/10.1371/ journal.pmed.1000316

Hull, L., Petrides, K.V., Allison, C., Smith, P., Baron-Cohen, S., Lai, M.-C. and Mandy, W. (2017) "'Putting on my best normal": Social camouflaging in adults with autism spectrum conditions'. Journal of Autism and Developmental Disorders, 47 (8), 2519-34. Online. https://doi. org/10.1007/s10803-017-3166-5

INVOLVE (2010) Payment for Involvement: A guide for making payments to members of the public actively involved in NHS, public health and social care research. Eastleigh: INVOLVE.

Jaswal, V.K. and Akhtar, N. (2019) 'Being versus appearing socially uninterested: Challenging assumptions about social motivation in autism'. Behavioral and Brain Sciences, 42, Article e82, 1-73. Online. https://doi.org/10.1017/S0140525X18001826

Jeste, D.V., Lee, E.E. and Cacioppo, S. (2020) 'Battling the modern behavioral epidemic of loneliness: Suggestions for research and interventions'. JAMA Psychiatry, 77 (6), 553-4. Online. https://doi.org/10.1001/jamapsychiatry.2020.0027

Kanner, L. (1943) 'Autistic disturbances of affective contact'. Nervous Child, 2, 217-50.

Lai, M.-C. and Baron-Cohen, S. (2015) 'Identifying the lost generation of adults with autism spectrum conditions'. The Lancet Psychiatry, 2 (11), 1013-27. Online. https://doi.org/10.1016/ s2215-0366(15)00277-1

Loukusa, S., Leinonen, E., Kuusikko, S., Jussila, K., Mattila, M.-L., Ryder, N., Ebeling, H. and Moilanen, I. (2007) 'Use of context in pragmatic language comprehension by children with Asperger syndrome or high-functioning autism'. Journal of Autism and Developmental Disorders, 37 (6), 1049-59. Online. https://doi.org/10.1007/s10803-006-0247-2

Martin, N. (2017) Encouraging Disabled Leaders in Higher Education: Recognising hidden talents (Stimulus Paper). London: Leadership Foundation for Higher Education.

McGraw, J.G. (1995) 'Loneliness, its nature and forms: An existential perspective'. Man and World, 28 (1), 43-64. Online. https://doi.org/10.1007/bf01278458

Milton, D.E.M. (2012) 'On the ontological status of autism: The "double empathy problem"'. Disability and Society, 27 (6), 883-7. Online. https://doi.org/10.1080/09687599.2012.710008

Milton, D.E.M. and Bracher, M. (2013) 'Autistics speak but are they heard?'. Medical Sociology, 7 (2), 61-9.

Milton, D.E.M., Heasman, B. and Sheppard, E. (2018) 'Double empathy'. In Volkmar, F.R. (ed.) Encyclopedia of Autism Spectrum Disorders. New York: Springer. Online. https://doi.org/10.1007/978-1-4614-6435-8_102273-1

Morrison, K.E., DeBrabander, K.M., Faso, D.J. and Sasson, N.J. (2019) 'Variability in first impressions of autistic adults made by neurotypical raters is driven more by characteristics of the rater than by characteristics of autistic adults'. Autism, 23 (7), 1817-29. Online. https://doi.org/10.1177/1362361318824104

National Autistic Society (2018) 'Hidden crisis: Autistic people four times more likely to be lonely than general public'. Online. www.autism.org.uk/get-involved/media-centre/news/2018-04-25hidden-crisis-autism-and-loneliness.aspx (accessed 14 August 2020).

Nicolaidis, C., Raymaker, D., Kapp, S.K., Baggs, A., Ashkenazy, E., McDonald, K., Weiner, M., Maslak, J., Hunter, M. and Joyce, A. (2019) 'The AASPIRE practice-based guidelines for the inclusion of autistic adults in research as co-researchers and study participants'. Autism, 23 (8), 2007-19. Online. https://doi.org/10.1177/1362361319830523

Nicolaidis, C., Raymaker, D., McDonald, K., Dern, S., Ashkenazy, E., Boisclair, C., Robertson, S. and Baggs, A. (2011) 'Collaboration strategies in nontraditional community-based participatory research partnerships: Lessons from an academic-community partnership with autistic selfadvocates'. Progress in Community Health Partnerships: Research, Education, and Action, 5 (2), 143-50. Online. https://doi.org/10.1353/cpr.2011.0022

Ochs, E. and Solomon, O. (2010) 'Autistic sociality'. Ethos, 38 (1), 69-92. Online. https://doi.org/ 10.1111/j.1548-1352.2009.01082.x

Pellicano, E. (2020) 'Commentary: Broadening the research remit of participatory methods in autism science - a commentary on Happé and Frith (2020)'. Journal of Child Psychology and Psychiatry, 61 (3), 233-5. Online. https://doi.org/10.1111/jcpp.13212 
Pellicano, E., Crane, L., Gaudion, K. and the Shaping Autism Research Team (2017) Participatory Autism Research: A starter pack. London: UCL Institute of Education.

Pellicano, L., Mandy, W., Bölte, S., Stahmer, A., Lounds Taylor, J. and Mandell, D.S. (2018) 'Editorial: A new era for autism research, and for our journal'. Autism, 22 (2), 82-3. Online. https://doi.org/10.1177/1362361317748556

Perlman, D. and Peplau, L.A. (1981) 'Toward a social psychology of loneliness'. In Duck, S. and Gilmour, R. (eds) Personal Relationships, 3: Personal relationships in disorder. London: Academic Press, 31-56.

Reed, M.S., Duncan, S., Manners, P., Pound, D., Armitage, L., Frewer, L., Thorley, C. and Frost, B. (2018) 'A common standard for the evaluation of public engagement with research'. Research for All, 2 (1), 143-62. Online. https://doi.org/10.18546/rfa.02.1.13

Rickard, W. and Purtell, R. (2011) 'Finding a way to pay in the UK: Methods and mechanisms for paying service users involved in research'. Disability and Society, 26 (1), 33-48. Online. https://doi.org/10.1080/09687599.2011.529665

Sasson, N.J., Faso, D.J., Nugent, J., Lovell, S., Kennedy, D.P. and Grossman, R.B. (2017) 'Neurotypical peers are less willing to interact with those with autism based on thin slice judgments'. Scientific Reports, 7, Article 40700, 1-10. Online. https://doi.org/10.1038/srep40700

Sheppard, E., Pillai, D., Wong, G.T.-L., Ropar, D. and Mitchell, P. (2016) 'How easy is it to read the minds of people with autism spectrum disorder?'. Journal of Autism and Developmental Disorders, 46 (4), 1247-54. Online. https://doi.org/10.1007/s10803-015-2662-8

Southby, K. (2017) 'Reflecting on (the challenge of) conducting participatory research as a researchdegree student'. Research for All, 1 (1), 128-42. Online. https://doi.org/10.18546/rfa.01.1.10

Stalker, K. and McArthur, K. (2012) 'Child abuse, child protection and disabled children: A review of recent research'. Child Abuse Review, 21 (1), 24-40. Online. https://doi.org/10.1002/car.1154

Stauffer, J. (2015) Ethical Loneliness: The injustice of not being heard. New York: Columbia University Press.

Sterponi, L. and De Kirby, K. (2016) 'A multidimensional reappraisal of language in autism: Insights from a discourse analytic study'. Journal of Autism and Developmental Disorders, 46 (2), 394-405. Online. https://doi.org/10.1007/s10803-015-2679-z

Sterponi, L. and Fasulo, A. (2010) " How to go on": Intersubjectivity and progressivity in the communication of a child with autism'. Ethos, 38 (1), 116-42. Online. https://doi.org/10.1111/ j.1548-1352.2009.01084.x

Sullivan, P.M. and Knutson, J.F. (2000) 'Maltreatment and disabilities: A population-based epidemiological study'. Child Abuse and Neglect, 24 (10), 1257-73. Online. https://doi.org/10.1016/ s0145-2134(00)00190-3

Tager-Flusberg, H. (1999) 'A psychological approach to understanding the social and language impairments in autism'. International Review of Psychiatry, 11 (4), 325-34. Online. https://doi.org/10.1080/09540269974203

Taylor, I. and Marrable, T. (2011) Access to Social Care for Adults with Autistic Spectrum Conditions. London: Social Care Institute for Excellence and University of Sussex.

Valtorta, N.K., Kanaan, M., Gilbody, S., Ronzi, S. and Hanratty, B. (2016) 'Loneliness and social isolation as risk factors for coronary heart disease and stroke: Systematic review and meta-analysis of longitudinal observational studies'. Heart, 102 (13), 1009-16. Online. https://doi.org/10.1136/heartjnl-2015-308790

Winnicott, D.W. (1971) Playing and Reality. London: Tavistock Publications.

Wong, A., Chau, A.K.C., Fang, Y. and Woo, J. (2017) 'Illuminating the psychological experience of elderly loneliness from a societal perspective: A qualitative study of alienation between older people and society'. International Journal of Environmental Research and Public Health, 14 (7), Article 824, 1-19. Online. https://doi.org/10.3390/ijerph14070824

Woods, R., Milton, D., Arnold, L. and Graby, S. (2018) 'Redefining critical autism studies: A more inclusive interpretation'. Disability and Society, 33 (6), 974-9. Online. https://doi.org/10.1080/096 87599.2018.1454380 